\title{
CONSTITUIÇÃO DE CURSOS A DISTÂNCIA ACESSÍVEIS: A IMPORTÂNCIA DO CONSULTOR DE ACESSIBILIDADE
}

Ana Virginia Isiano Lima ${ }^{1}$, Klaus Schlünzen Junior ${ }^{1,2}$, Danielle Aparecida do Nascimento dos Santos ${ }^{3}$, Ana Mayra Samuel da Silva ${ }^{1}$.

${ }^{1}$ Universidade Estadual Paulista - UNESP, Programa de Pós-Graduação em Educação (PPGE). ${ }^{2}$ Departamento de Estatística, Presidente Prudente, SP. ${ }^{3}$ Universidade do Oeste Paulista - UNOESTE, Programa de Pós-Graduação em Educação, Presidente Prudente, SP. E-mail: anaisianolima@gmail.com.

\section{RESUMO}

A Educação a Distância (EaD) ganha cada vez mais espaço no cenário educacional. Diante do crescimento expressivo dessa modalidade no contexto educativo, não se pode negar a busca por formação dos Estudantes Público-Alvo da Educação Especial (EPAEE). Evidencia-se, assim, a necessidade de se construir materiais que contenham recursos de acessibilidade. Dentre os recursos disponíveis, abordaremos neste trabalho a audiodescrição, que foi vivenciada durante o curso intitulado "Princípios e Técnicas da Audiodescrição: aplicabilidade em contextos culturais e educacionais", oferecido pelo Núcleo de Educação a Distância (NEaD), da Universidade Estadual Paulista "Júlio de Mesquita Filho" (UNESP). O estudo objetivou compreender a função do consultor de acessibilidade com deficiência visual. A proposta metodológica utilizada foi a abordagem qualitativa. Os resultados evidenciam que as sugestões e orientações do consultor de acessibilidade tornam os materiais de um curso acessíveis, pois consideram possíveis equívocos que podem impedir a compreensão dos estudantes em relação ao conteúdo.

Palavras-Chave: Educação a Distância, Audiodescrição, Deficiência Visual, Consultor de Acessibilidade, Acessibilidade.

\section{CONSTITUTION OF ACCESSIBLE DISTANCE COURSES: THE IMPORTANCE OF THE ACCESSIBILITY CONSULTANT}

\begin{abstract}
Distance Education (EaD) gains more space in the educational scenario. Faced with the expressive growth of this modality in the educational context, it is not possible to deny the quest for the students with disabilities. Thus, the need to build materials containing accessibility features is evidenced. Among the available resources, we will cover the audiodescription, which was experienced during the course entitled "Principles and Techniques of Audiodescription: applicability in cultural and educational contexts", offered by the Nucleus of Distance Education (NEaD), São Paulo State University (UNESP). The study aimed to understand the role of the accessibility consultant with visual impairment. The methodological proposal used was the qualitative approach. The results show that the suggestions and orientations of the accessibility consultant make the materials of a course accessible as they consider possible misunderstandings that may impede students' understanding of the content.
\end{abstract}

Keywords: Distance Education, Audiodescription, Visual Disability, Accessibility Consultant, Accessibility. 


\section{INTRODUÇÃO}

A Educação a Distância (EaD), desenvolvida em nosso país, assumiu diferentes características ao longo de sua instituição, constituindo-se, inicialmente, como uma proposta de ensino em que as atividades eram distribuídas de forma impressa. Schlünzen Junior (2009) enfatiza que durante esse processo outros projetos foram desenvolvidos, alterando, assim, as concepções que envolviam o ensino na modalidade a distância. Conforme o autor, os avanços tecnológicos evidenciados nos últimos anos, trouxeram uma nova perspectiva a EaD, que considerou as tecnologias como recursos capazes de oferecer situações de ensino e aprendizagem para os estudantes que se encontravam em regiões menos favorecidas ou que não possuíam condições de acessar e permanecer em instituições presenciais (SCHLÜNZEN JUNIOR, 2009).

Assim, evidencia-se que a EaD, desenvolvida em Ambientes Virtuais de Aprendizagem (AVA), ganha cada vez mais espaço no cenário educacional. O Censo do Ensino Superior do Instituto Nacional de Estudos e Pesquisas Educacionais Anísio Teixeira (INEP), referente ao ano de 2012, expressa que o número de estudantes ingressos em cursos superiores públicos e privados, oferecidos a distância, ultrapassa a marca de um milhão de matrículas, demonstrando, assim, o crescimento expressivo dessa modalidade no contexto educativo.

Considerando a crescente demanda, não se pode negar a presença e a busca por formação dos Estudantes Público-Alvo da Educação Especial (EPAEE), que, historicamente, enfrentaram entraves que impossibilitaram o desenvolvimento de sua escolarização em instituições presenciais. Diante das situações de exclusão vivenciadas por esses estudantes, a Constituição Federal Brasileira (1998) e a Lei de Diretrizes e Bases para Educação Nacional (LDBEN) n⒐394 de 1996 estabelecem que todos os estudantes têm direito a educação, cabendo ao Estado oferecer condições para que os sistemas de ensino a ofereçam com qualidade. Com base nesses princípios, os marcos legais que norteiam a Educação Especial e Inclusiva em nosso país apontam que as práticas educativas devem garantir a participação e a permanência dos EPAEE, que, ao ingressarem ao Ensino Superior devem ter acesso a ações que envolvem o planejamento e a organização de recursos que possibilitem a efetiva participação nas atividades de ensino e aprendizagem desenvolvidas durante o curso (BRASIL, 2008).

Diante dessas premissas, há a necessidade de se planejar e oferecer cursos a distância que "tenham como pressuposto que os estudantes matriculados conseguirão estudar, sem prejuízo no acesso aos conteúdos por barreiras de ordem comunicacional e de usabilidade" (RIOS et al, 2016, p. 332). Para isso, as propostas educacionais devem ser acessíveis aos EPAEE para que, a partir de suas especificidades, possam avançar em sua escolarização e na construção da aprendizagem de forma significativa.

A acessibilidade, de acordo com a Lei № 10.098/2000, refere-se a

[...] possibilidade e condição de alcance para utilização, com segurança e autonomia, dos espaços, mobiliários e equipamentos urbanos, das edificações, dos transportes e dos sistemas e meios de comunicação, por pessoa portadora de deficiência ou com mobilidade reduzida (BRASIL, 2000, p. 1).

Considerando os cursos oferecidos na modalidade a distância, faz-se necessário a garantia de acessibilidade arquitetônica, que deve ser ofertada nos polos presenciais, bem como, o desenvolvimento de materiais didáticos e recursos do AVA acessíveis, que promovem a autonomia dos EPAEE na construção de sua aprendizagem. Rios et al (2015) evidencia que o material didático produzido sem recursos de acessibilidade dificulta a formação dos estudantes com deficiência no Ensino Superior, impedindo, assim, a continuidade em seus estudos. Por isso, a acessibilidade garante o acesso e a permanência desses estudantes nos cursos em EaD, que, devido à distância espacial e temporal, exigem a interação e a construção do conhecimento de forma autônoma. 
No que se refere aos cursos desenvolvidos no AVA, a acessibilidade digital "está definida pela capacidade de um determinado produto ser flexível o suficiente para atender as necessidades e preferências do maior número possível de pessoas" (MARI, 2011, p. 25 apud RIOS et al, 2016, p. 333), ou seja, garante o acesso a qualquer recurso, material didático ou atividade oferecida pelo curso.

Diante dessas premissas, evidencia-se a necessidade de se construir materiais didáticos e propostas educativas que contenham recursos de acessibilidade. Dentre os mecanismos disponíveis, abordaremos neste trabalho a audiodescrição, que se configura como um recurso de Tecnologia Assistiva (TA) que promove o acesso ao conteúdo imagético dos cursos para os estudantes com Deficiência Visual (DV). Para isso, destacaremos a experiência vivenciada no curso intitulado "Princípios e Técnicas da Audiodescrição: aplicabilidade em contextos culturais e educacionais", oferecido pelo Núcleo de Educação a Distância (NEaD), da Universidade Estadual Paulista "Júlio de Mesquita Filho" (UNESP), que, durante as atividades propostas, promoveu o contato dos cursistas com um consultor de acessibilidade que possuía deficiência visual.

Dessa forma, o objetivo deste estudo foi compreender a função do consultor de acessibilidade com deficiência visual, enquanto o profissional responsável para a orientação e a validação da audiodescrição em cursos a distância. Para isso, apresentaremos os procedimentos metodológicos adotados neste estudo, os resultados evidenciados e as reflexões oriundas deste trabalho.

\section{METODOLOGIA}

Diante do objetivo elencado, a proposta metodológica utilizada neste estudo foi a abordagem qualitativa. De acordo com Lüdke e André (1995, p.13) a abordagem qualitativa de pesquisa "[...] envolve a obtenção de dados descritivos, obtidos no contato direto do pesquisador com a situação estudada, enfatiza mais o processo do que o produto e se preocupa em retratar a perspectiva dos participantes [...]".

Bogdan e Biklen (1994) definem que a investigação qualitativa possui cinco características, que se expressam em grande parte dos estudos desenvolvidos com base nessa abordagem, a saber:

1. Na investigação qualitativa a fonte direta de dados é o ambiente natural, constituindo o investigador o instrumento principal [...].

2. A investigação qualitativa é descritiva [...].

3. Os investigadores qualitativos interessam-se mais pelo processo do que simplesmente pelos resultados ou produtos [...].

4. Os investigadores qualitativos tendem a analisar os seus dados de forma indutiva [...].

5. O significado é de importância vital na abordagem qualitativa [...]. (BOGDAN e BIKLEN, 1994, p. 47-50).

A partir das concepções que envolvem essa abordagem, compreendemos que, durante este estudo, os dados foram coletados de forma descritiva, pois buscamos compreender a participação do consultor de acessibilidade com deficiência visual na orientação e validação de um roteiro audiodescrito.

Para que isso se efetivasse, atuamos mediante a aprovação do Comitê de Ética em Pesquisa (CEP), sendo o número do Certificado de Apresentação para Apreciação Ética (CAAE): 10206912.2.0000.5402 e mediante o uso da observação. Conforme Marconi e Lakatos (2007, p. 88) a observação "é uma técnica de coleta de dados para conseguir informações e utiliza os sentidos na obtenção de determinados aspectos da realidade. Não consiste apenas em ver e ouvir, mas também em examinar fatos ou fenômenos que se deseja estudar". Assim, a partir dessa 
técnica, é possível que um fenômeno seja compreendido em diferentes âmbitos (MARCONI e LAKATOS, 2007).

\section{RESULTADOS}

O curso "Princípios e Técnicas da Audiodescrição: aplicabilidade em contextos culturais e educacionais", oferecido pelo NEaD - UNESP, ocorreu no período de julho a dezembro de 2016 e, objetivava apresentar os fundamentos, técnicas e princípios que norteavam a audiodescrição, bem como, oferecer subsídios para a elaboração de roteiros audiodescritos. Para que os objetivos do curso fossem alcançados as atividades foram realizadas em sete módulos, que envolviam leituras, fóruns de discussão e o desenvolvimento de atividades práticas em relação à temática.

Ao vivenciarmos as atividades propostas, verificamos que, a partir dos subsídios teóricos disponibilizados, os estudantes tiveram a oportunidade de desenvolver atividades práticas que envolviam aspectos relacionados a audiodescrição, como a elaboração de roteiros audiodescritos. Durante esse processo, a mediação dos tutores foi fundamental para a construção da aprendizagem em relação às concepções que envolviam a audiodescrição, pois, por se tratar de uma modalidade de tradução audiovisual, era necessário o entendimento dos princípios e técnicas que norteiam a sua elaboração.

Considerando o objetivo deste estudo, destacaremos uma atividade realizada no último módulo do curso, que proporcionou aos estudantes o desenvolvimento de um roteiro audiodescrito a partir da orientação e da validação de um consultor de acessibilidade com deficiência visual. Para que a atividade fosse executada, os estudantes foram divididos em grupos e, a partir do fórum de discussão, tiveram a oportunidade de elaborar um roteiro audiodescrito para uma imagem disponibilizada pelos tutores, expressa na Figura 1.

Figura 1. Imagem disponibilizada durante a atividade.

\section{Representação no circuito}

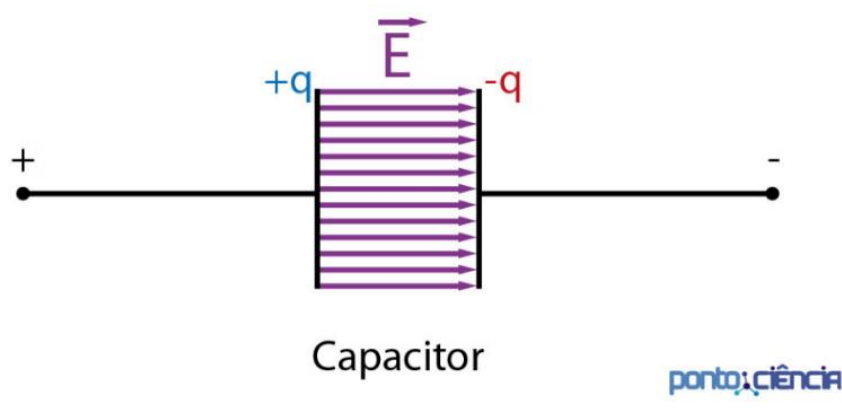

Fonte: disponibilizada pela autora.

Para que a imagem fosse descrita, os integrantes de um dos grupos se organizaram de maneira que todos atuassem colaborativamente na construção do roteiro. Assim, cada estudante elaborou uma descrição em um editor de texto, para que, durante o processo de construção, verificassem o roteiro que mais se adequava às técnicas e princípios estabelecidos pela audiodescrição, como expresso na Figura 2. 
Figura 2. Roteiro desenvolvido por um dos grupos.

NOTAS PROÊMIAS: Circuito elaborado pelo Professor de Física Gianinni Pelizer, do Ponto Ciência,

em 2011. Imagem disponível em:

http://www.pontociencia.org.br/experimentos/visualizar/identificando-elementos-de-umcircuito/751.

INÍCIO DA DESCRIÇÃO: Em um fundo branco há um circuito. Acima há os dizeres escritos em preto: "Representação no Circuito" e na parte inferior está escrito: "Capacitor". À direita na parte inferior o logotipo do Ponto Ciência. Esquema representativo no circuito: à esquerda, linha horizontal com uma pequena esfera preta interligada no seu início, acima da esfera o sinal de positivo, uma linha vertical corta a horizontal, acima dela o sinal de mais e a letra "q" minúscula, ambos na cor azul, encostadas na linha vertical treze setas na cor roxa apontam para a horizontal e são cercadas por uma linha vertical, acima das setas a letra " $E$ " maiúscula e acima dela uma pequena seta apontando para a direita no mesmo sentido das outras, ambos na cor roxo. Acima da linha vertical o sinal de menos e a letra " $q$ " minúscula, ambos na cor vermelha. Interligada a linha vertical segue a linha horizontal com uma pequena esfera preta no final, acima da esfera o sinal de negativo. FIM DA DESCRIÇÃO.

Fonte: disponibilizada pela autora.

A partir da contribuição de cada estudante, o grupo definiu a versão final do roteiro audiodescrito, para que, assim, o consultor de acessibilidade com deficiência visual pudesse avaliar e validar a descrição realizada. Após a leitura do roteiro, o consultor pontuou: "gostei da descrição do circuito. Só uma coisa, me parece que a linha horizontal liga as duas esferas, correto? Se sim, podemos falar isso já no início para facilitar a descrição" (consultor de acessibilidade).

Diante do apontamento realizado, compreendemos que as sugestões e orientações do consultor de acessibilidade tornam os materiais de um curso acessíveis, pois consideram possíveis equívocos que podem impedir a compreensão do estudante em relação ao conteúdo. Conforme Mianes (2016, p.13), "o consultor é aquele que realiza o controle de qualidade do produto a partir do ponto de vista dos usuários do recurso". De acordo com o autor, o consultor com deficiência visual atesta o produto enquanto usuário e verifica a sua eficiência, para que, assim, o material seja disponibilizado para os estudantes do curso (MIANES, 2016).

Bataliotti et al (2016) enfatiza que a acessibilidade possibilita o acesso e a permanência de mais estudantes em cursos a distância, minimizando a evasão. Compreendemos, assim, que a produção de materiais didáticos, atividades, AVA's e outras ferramentas que envolvem essa modalidade de ensino, deve considerar as especificidades dos EPAEE e os recursos de acessibilidade que promovem a participação e a construção da aprendizagem de forma autônoma. Por isso, a presença de um consultor de acessibilidade com deficiência visual é essencial para a constituição de cursos que atendam a todos os estudantes.

\section{DISCUSSÃO}

A constituição de um curso acessível requer o desenvolvimento e a implementação de recursos que promovam o acesso e a permanência de todos os estudantes. Para que isso se efetive, Rios et al (2016) enfatiza que a cultura inclusiva deve fazer parte da equipe que planeja e elabora os cursos desenvolvidos a distância, para que, assim, as especificidades e as diferenças dos estudantes sejam valorizadas. A cultura inclusiva "se configura em mudança atitudinal dos profissionais, visto que eles têm a responsabilidade de produzir materiais acessíveis para que 0 estudante com deficiência, que está na ponta do processo, tenha acesso ao conteúdo sem barreiras" (RIOS et al, 2016, p. 334).

Estudos como o de Bataliotti (2016), Mianes (2016) e Rios et al (2016) apontam que a constituição de uma equipe multidisciplinar favorece a produção e a implementação de recursos acessíveis, pois, a partir do entendimento de que todos os estudantes devem acessar o curso com autonomia, cada membro da equipe irá atuar, conforme sua especialidade, no desenvolvimento de produtos de acessibilidade. No que se refere a atuação do consultor de acessibilidade, compreendemos que a atuação desse profissional favorece a constituição de cursos e materiais 
acessíveis, pois, ao identificar possíveis erros, os materiais são refeitos, considerando as especificidades dos estudantes com deficiência.

\section{CONCLUSÃO}

A partir das ações vivenciadas no curso "Princípios e Técnicas da Audiodescrição: aplicabilidade em contextos culturais e educacionais", compreendemos que a atuação de consultores de acessibilidade com deficiência visual favorece a implementação e a validação dos recursos acessíveis, pois, a partir da avaliação desse profissional, os erros presentes nos roteiros audiodescritos podem ser corrigidos, minimizando, assim, as dificuldades que podem ser encontradas pelos estudantes durante a realização do curso. Cabe destacar, que o consultor de acessibilidade deve conhecer os princípios que norteiam a audiodescrição, para que, assim, a validação ocorra de forma significativa.

Assim, para atuarmos no desenvolvimento de cursos a distância acessíveis, é necessário a constituição de uma equipe que valorize as diferenças existentes entre os estudantes e que busque caminhos para que todos atuem ativamente na construção de seu conhecimento. A implementação da audiodescrição se configura como um recurso que promove o acesso, a permanência e a autonomia do cursista com deficiência visual. Porém, ao considerarmos todos os estudantes que participam de cursos oferecidos a distância, devemos atuar na elaboração de materiais que favoreçam a autonomia de todos.

\section{REFERÊNCIAS}

BATALIOTTI, S. E. et al. A construção de objetos educacionais acessíveis. Journal of Research in Special Educational Needs, v. 16, n. 1, p. 41 - 45, 2016, https://doi.org/10.1111/1471-3802.12266.

BOGDAN, R.; BIKLEN, S. Investigação qualitativa em educação: uma introdução à teoria e aos métodos. Porto: Porto editora, 1994.

BRASIL. Constituição da República Federativa do Brasil. Brasília: Senado Federal, 1988.

BRASIL. Lei de Diretrizes e Bases da Educação Nacional: no 9394/96. Brasília: Senado Federal, 1996.

BRASIL. Casa Civil. Lei $n^{\circ}$ 10.098, de 19 de dezembro de 2000. Estabelece normas gerais e critérios básicos para a promoção da acessibilidade das pessoas portadoras de deficiência ou com mobilidade reduzida, e das outras providências. Diário Oficial da União, Brasília, DF, 20 dez. 2000. <http://www.planalto.gov.br/ccivil_03/LEIS/L10098.htm>. Acesso em: 20 fev. 2017.

BRASIL: Ministério da Educação. Secretaria de Educação Especial. Política Nacional de Educação Especial na Perspectiva da Educação Inclusiva. Brasília: MEC/SEESP, 2008.

INSTITUTO NACIONAL DE ESTUDOS E PESQUISAS EDUCACIONAIS ANÍSIO TEIXEIRA (INEP, 2012). Censo da Educação Superior - 2012: resumo técnico. Brasília: Instituto Nacional de Estudos e Pesquisas Educacionais Anísio Teixeira.

LUDKE, M; ANDRÉ, M. E. D. A. Pesquisa em Educação: Abordagens Qualitativas. São Paulo: E.P.U, 1995.

MARI, C. M. M. Avaliação da acessibilidade e da usabilidade de um modelo de ambiente virtual de aprendizagem para a inclusão de deficientes visuais. 96 f. Dissertação (Mestrado em Engenharia 
de Produção) - Centro de Ciências Exatas e de Tecnologia, Universidade Federal de São Carlos, São Carlos, 2011.

MARCONI, M. A.; LAKATOS, E. M. Técnicas de Pesquisa. São Paulo: Editora Atlas S.A., 2007.

MIANES, F. L. Consultoria em audiodescrição: alguns caminhos e possibilidades. In: CARPES, D. S. Audiodescrição: práticas e reflexões. Santa Cruz do Sul: Editora Catarse, 2016. P. 10 - 21.

RIOS, G. A. et al. Produção de materiais didáticos digitais audiodescritos: experiências do Núcleo de Educação a Distância da Unesp. Revista InFor, v. 1, n.1, 2015, p. 95- 109, 2015.

RIOS, G. A. et al. Cultura inclusiva na Educação a Distância: concepções de cursos acessíveis. Journal of Research in Special Educational Needs, v. 16, n. 1, p. 332 - 335, 2016, https://doi.org/10.1111/1471-3802.12156.

SCHLÜNZEN JUNIOR, K. Educação a distância no Brasil: caminhos, políticas e perspectivas. ETD Educação Temática Digital, Campinas, 10(2), pp. 16-36. 